\title{
Probabilistic Design with Gerber Fatigue Model
}

\author{
Edward E. Osakue ${ }^{1}$ \\ ${ }^{1}$ Department of Industrial Technologies, Texas Southern University, Houston, USA \\ Correspondence: Edward E. Osakue, Department of Industrial Technologies, Texas Southern University, 3100 \\ Cleburne St., Houston, TX 77004, USA. Tel: 1-832-316-3279. Email: osakueee@tsu.edu
}

Received: January 10, 2013

Accepted: February 7, 2013 Online Published: February 21, 2013

doi:10.5539/mer.v3n1p99

URL: http://dx.doi.org/10.5539/mer.v3n1p99

\begin{abstract}
This paper presents a probabilistic design approach for the Gerber bending fatigue failure rule using sensitivity-based analysis. The design model parameters are considered as random variables that are characterized by mean values and coefficients of variation (covs). The coefficient of variation of a design parameter is obtained by using first order Taylor series expansion for strength and stress in a stress-based fatigue design. A reliability factor is determined based on the coefficients of variation and a failure probability. The reliability factor is then used for design sizing and analysis.

Probabilistic design allows a quantification of risk that is not possible with deterministic design approaches. This risk quantification can help to avoid over- or under-design problems while ensuring that safety and quality levels are economically achieved. Over design requires more resources than necessary and leads to costly products. Avoiding over-design helps to conserve product materials and reduce manufacturing resources, machining accuracy, quality control, and processing. Under-designed products are prone to failures, making the products unsafe and unreliable. This increases the risks of product liability lawsuits, customer dissatisfaction, and even accidents.

This study shows a $51 \%$ reduction in component size without compromising desired reliability and hence a possible $51 \%$ reduction in component mass and cost. Therefore, significant savings in product cost can be obtained through probabilistic design. Probabilistic design seems to be the most practical approach in product design due to the inherent variability associated with service loads, material properties, geometrical attributes, and mathematical design models. It is becoming the preferred design method because over- or under-design can be avoided while still ensuring the safety of a product.
\end{abstract}

Keywords: fatigue, failure, lognormal, variate, reliability, design, factor, safety

\section{Introduction}

In today's market environment, quality is taken for granted. A quality product is associated with rare unexpected and unpleasant events which result from uncertainties in design. Customers are usually satisfied if a product performs as expected or better ("Understanding Probabilistic Design"). Designing a quality product is therefore of paramount importance for product market success. In traditional or deterministic design, safety or design factors are usually subjectively assigned in product design so as to assure reliability. But this method of design can sometimes be crude. In fact, the safety factor method does not give insight about individual variation or the actual margin of safety in a design (Koch, 2002). Because of the difficulty of relating safety factor and product safety quantitatively, some prefer the term design factor to safety factor (Mott, 2008).

According to Kalpakjian and Schmid (2001), surveys indicate that many products in the past have been overdesigned. Over design can result from uncertainty in design calculations, or from concerns about product safety. For instance in order to avoid user injuries or death and product liability lawsuits, a larger then necessary safety factor may be used in a design. Also, many designs are based on experience and intuition, rather than thorough analysis and experimentation which may result in over- or under-design. Overdesign can add significantly to the cost of a product making it uneconomical because components or products become too bulky, are made with unwarranted manufacturing precision and, or are made with unwarranted material quality. However, under-design increases risk of failure and product liability issues. Probabilistic design allows product design to be safe and reliable while avoiding costly over-design. It conserves materials and manufacturing resources in machining processes, accuracy, and quality control. 
Probabilistic design deals with the consideration of the effects of random variation on design model parameters. Very few real engineering problems are void of uncertainty because variation is inherent in material properties, loading conditions, geometric properties, simulation models, manufacturing precision, and actual product usage (Koch, 2002). Specifically, in machine and structural design, random variation is known in structural capability such as yield strength, fatigue strength, and ultimate strength. Likewise loads on members are subject to random variation. For instance, static loads are considered fixed or deterministic in values while dynamic loads are known to vary in magnitude and or with time. Manufacturing processes are associated with variability, so tolerances are specified on component dimensions. In general, variability in stress-based design parameters can be grouped into two: strength variability and stress variability. Stress variability has two components of load variability and geometry variability. It is not physically possible or financially feasible to eliminate variation of design parameters. This is due to the fact that the reduction of variability is associated with higher costs either through better and more precise manufacturing methods and processes or increased efforts in quality control.

Due to known variation in many design model parameters, a statistical consideration of load, stresses, deformations, etc. is a logical expectation in engineering design. This is because statistical methods allow quantitative descriptions of phenomena that show consistent pattern of variability (Mischke, 1996). Accepting variability and limiting it seems to be a more practical approach in design as it makes production more cost-effective and products more affordable ("Understanding Probabilistic Design"). Probabilistic design treats design model parameters as random variables and allows an assessment of risk or confidence in a design and can quantify the amount of over- or under-design (Cullimore \& Tsuyuki, 2002). Random variable analysis shows that mean values of functional relationships are obtained by substituting mean values of the variates. Therefore, calculations of safety factor based on the quotient of minimum strength and maximum load or maximum stress are not appropriate when considering chance failure (Mischke, 1996). Using statistical methods, component or product safety can be quantitatively associated with a probability of failure. This approach has led to the concept of a reliability factor (Taguchi, 1992; Shigley \& Mittchel, 1983). The reliability factor is evaluated using mean and standard deviation (or coefficient of variation) values in the appropriate mathematical design models. This is the basic conceptual difference between safety factor (a somewhat arbitrary number) and reliability factor which is expressed as a function of design parameter variability and a failure level.

The use of probabilistic design methods requires some appropriate probability distribution (Johnson, 1980). It is known that products of variates from any distribution tend asymptotically to lognormal (Mischke, 1996). Also, products, quotients, and exponents of lognormal variates are also lognormals. Since design formulas generally contain products and quotients of design parameters or sum of terms of products and quotients of the design parameters, the lognormal distribution is a good candidate for probabilistic design applications. It has been suggested that the lognormal distribution is more accurate than the normal distribution in situations of high reliability (Reshetov, Ivanov, \& Fadeev, 1980). Also, lognormal distribution for design parameters is reasonable because of the control of material properties and the positive skewness of known load distribution curves (JJS). In particular, fatigue failure data exhibit lognormal distribution in an approximate sense (Shigley \& Mischke, 1996). Generally, computation of sample mean and standard deviation allows the estimation of probability of failure (Collins, Busby, \& Staab, 2010).

The numerical value of reliability factor should take both the consequence of failure and the nature of product usage into account. Product usage in service is not easy to predict at the design phase (Norton, 2000). For instance, the user may not follow operational guidelines; service environment may be different from that assumed during design, and in fact, a host of variables completely outside the control of the designer come into play. Most often designers resort to the use of overload or service factors in estimating the maximum load expected in service (Collins, Busby, \& Staab, 2010; Childs, 2004; Spotts, 1985; Juvinall, 1983). Generally, the variability of size dimensions is usually of a lesser degree compared to the variability in material properties or loads. Apparently, failure probability should be chosen to reflect the consequence of failure such as product damage or personnel injury (Collins, Busby, \& Staab, 2010; Juvinall, 1983; Shigley \& Mischke, 1996). For instance, a cheap and easily replaced component may be designed for low reliability, say $90 \%$. However, if a component failure would result in severe product damage or possible personnel injury, a low failure probability is desirable. Now if a failure can result in fatality, then very high reliability must the required. Ashby and Jones (1987) says a failure probability of $10^{-1}$ may be acceptable for ceramic tool because it is easily replaced but one may aim at a value of $10^{-6}$ where failure may result in injury and probably $10^{-8}$ when one component failure could be fatal. The aerospace industry specifies a reliability of "five-nines" (i.e., 0.99999 or a failure probability of $10^{-5}$ ) in many cases, while the standard reliability of rolling element bearings is $90 \%$ (Collins, Busby, \& Staab, 2010). 
The most problematic design situation is dynamic where machine and structural members are loaded by forces which may vary in magnitude and or point of application. This leads to variation in the stress levels on members that can cause fatigue failure. Fatigue failure normally takes the form of brittle fracture at stresses well below the static strength of the materials (Hidgon, Osheen, Stiles, \& Weesa; 1967). About $80 \%$ to $90 \%$ of the failures of machine and structural members result from fatigue (Kravchenko, 1964; Sachs, 1999). Because of the predominance of fatigue failure, the objective of this study is to develop probabilistic design model for the traditional Gerber bending fatigue model by considering design parameters as random variables. The model is a good candidate for probabilistic application because it captures experimental data on an average performance (Norton, 2000; Shigley \& Mischke, 1996) basis and thus can be associated with a 50\% probability. There are at least three approaches in probabilistic designs; namely Monte Carlo simulation, design of experiments, and sensitivity analysis (Koch, 2002). These methods help us estimate the means and standard deviations of design parameters necessary for probabilistic designs. This study uses the sensitivity analysis approach which is considered appropriate and cost effective in component design for structural and mechanical applications. If reliable data values of means and standard deviations or coefficients of variation of design parameters are available in fatigue design situation, a definite reliability goal can be met through a reliability factor using the lognormal probability distribution.

\section{Lognormal Reliability Model}

In the physical domain, $S$ is the random variable for strength and $\sigma$ is the random variable for stress. By definition, the reliability factor in a design is taken as:

$$
n_{z}=\frac{\mu_{S}}{\mu_{\sigma}}
$$

Assuming that $S$ and $\sigma$ have lognormal distributions, respectively, then random variables $x$ and $y$ can be defined as:

$$
\begin{aligned}
& x=\operatorname{In}(S) \\
& y=\operatorname{In}(\sigma)
\end{aligned}
$$

The means and standard deviations of $x$ and $y$ are given in Equations 3 and 4, ("Lognormal Distribution") respectively:

$$
\begin{gathered}
\mu_{x}=\operatorname{In}\left(\mu_{S}\right)-0.5 \operatorname{In}\left(1+v_{s}^{2}\right) \\
\mu_{y}=\operatorname{In}\left(\mu_{\sigma}\right)-0.5 \operatorname{In}\left(1+v_{\sigma}^{2}\right) \\
s_{x}=\sqrt{\operatorname{In}\left(1+v_{S}^{2}\right)} \\
s_{y}=\sqrt{\operatorname{In}\left(1+v_{\sigma}^{2}\right)}
\end{gathered}
$$

When a component is loaded, an interaction between strength variable $x$ and the stress variable $y$ occurs as depicted in Figure 1. The shaded portion in Figure 1 represents the region where the imposed stress is likely to be greater than the strength of the component. Hence this region represents the zone of possible failure.

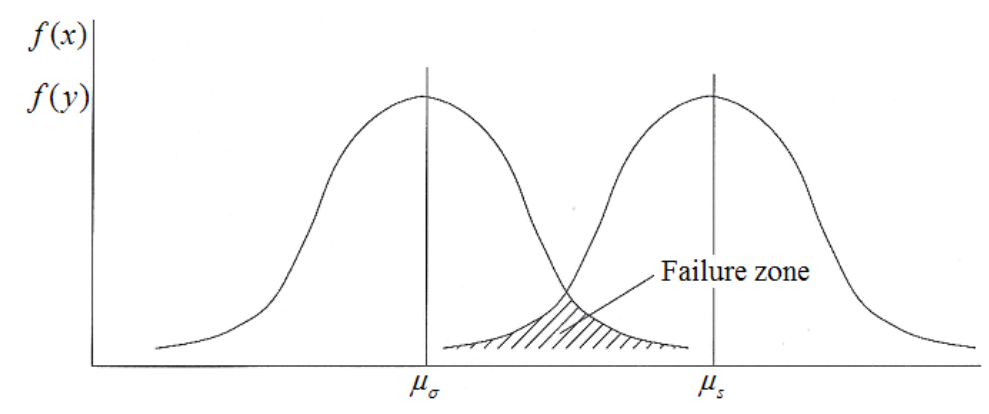

Figure 1. Load-strength interaction 
The failure zone is defined by the probability density function $\mathrm{q}$, the difference between random variables $x$ and $y$. That is:

$$
q=x-y
$$

The parameters (mean and standard deviation) of the interaction random variable, $q$ in Figure1 are:

$$
\begin{gathered}
\mu_{q}=\operatorname{In}\left(\frac{\mu_{S}}{\mu_{\sigma}}\right)-0.5 \operatorname{In}\left(\frac{1+v_{S}^{2}}{1+v_{\sigma}^{2}}\right) \\
s_{q}=\sqrt{\operatorname{In}\left\{\left(1+v_{S}^{2}\right)\left(1+v_{\sigma}^{2}\right)\right\}}
\end{gathered}
$$

Figure 2a depicts the distribution of $q$ while Figure $2 \mathrm{~b}$ depicts the corresponding unit normal variate distribution of $q$. In Figure 2a, any normal variate $q$ on the left of the mean $\mu_{q}$ can be obtained using the unit normal variate $z$.

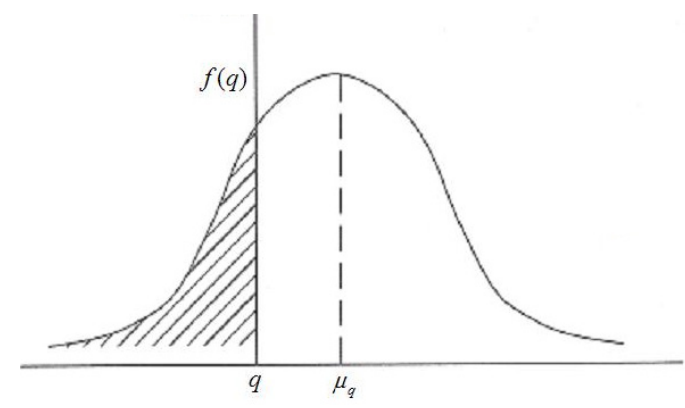

a) Failure distribution curve

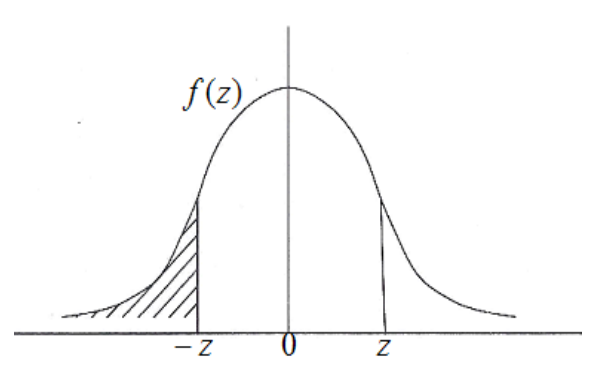

b) Unit normal distribution

Figure 2. Failure random variable

The failure zone is the region of $q \leq 0$. Hence failure is predicted when:

$$
\begin{gathered}
q=\mu_{q}-z s_{q}=0 \\
z=\frac{\mu_{q}}{s_{q}}=\frac{\operatorname{In}\left(n_{z}\right)-0.5 \operatorname{In}\left(\frac{1+v_{S}^{2}}{1+v_{\sigma}^{2}}\right)}{\sqrt{\operatorname{In}\left\{\left(1+v_{S}^{2}\right)\left(1+v_{\sigma}^{2}\right)\right\}}}
\end{gathered}
$$

The failure probability associated with the unit normal variate is represented by the area under the unit normal distribution curve (shaded in Figure 2b). The corresponding reliability is obtained by subtracting the failure probability from unity. That is:

$$
\begin{gathered}
R_{z}=1-\Phi(-z)=\Phi(z) \\
n_{z}=\exp \left[z \sqrt{\operatorname{In}\left\{\left(1+v_{S}^{2}\right)\left(1+v_{\sigma}^{2}\right)\right\}}+0.5 \operatorname{In}\left(\frac{1+v_{S}^{2}}{1+v_{\sigma}^{2}}\right)\right]
\end{gathered}
$$

Equation 8a gives the reliability for the unit normal variate z, with the value of $\Phi(-z)$ or $\Phi(z)$ read from an appropriate table. Equation $8 \mathrm{~b}$ gives the reliability factor for a desired reliability level defined by $z$. If a desired reliability or failure probability is specified, then $z$ is known and the necessary reliability factor $n_{z}$ for achieving this reliability can be obtained. Therefore, if the variability of the significant factors in a design model can be estimated with reasonable accuracy, it is possible to design to a reliability level through a reliability factor. According to Wang, Kim and Kim (2006), it is common to use the unit normal variate (Equation 7b) for failure probability assessment because probability values (Equation 8a) can change by several orders of magnitude over 
small changes in the unit normal variate. The task in using the reliability model of Equation $8 \mathrm{~b}$ is to develop expressions for $v_{S}$ and $v_{\sigma}$ for specific design models. The model application is not limited to stress-based design; it can be used for any serviceability criterion of interest such as lateral stability, transverse deflection, torsional rigidity, critical speed, etc. In the Appendix, expressions for $v_{S}$ and $v_{\sigma}$ for Gerber bending fatigue failure rule are developed.

\section{Gerber Bending Fatigue Model}

Figure 3 shows the Gerber bending fatigue design diagram. The stress state in bending fatigue loading is appraised from the maximum and minimum stress values imposed on the structural or machine member during one load cycle. The exact variation of the stress during the cycle does not seem to be particularly relevant (Kravchenko, 1964; Dieter, 1976). The damage from cyclic bending stress state is assessed on the basis of the mean and amplitude stresses. When a tensile mean stress is present during fatigue load cycle, the material fails at alternating stress levels lower than the fatigue strength. In Figure 3, the Gerber fatigue failure rule is represented by the Gerber curve ABC. The design space is divided by the line OB into two regions OAB called dynamic fatigue failure regime and $\mathrm{OBC}$ called static fatigue failure regime (Osakue, 2012; Osakue, Anetor, \& Odetunde, 2012). In region $\mathrm{OAB}$, material failure results from the predominant influence of the alternating stress. In region OBC material failure results from the predominant influence of the mean stress. Line OB makes angle $\beta$ with the horizontal line. The angle $\beta$ is a function of the service fatigue and tensile strengths of materials (Osakue, 2012; Osakue, Anetor, \& Odetunde, 2012):

$$
\begin{gathered}
\psi_{s}=\frac{S_{f}}{S_{u}} \\
\tan \beta=\eta_{t}=1.5 \psi_{s}
\end{gathered}
$$

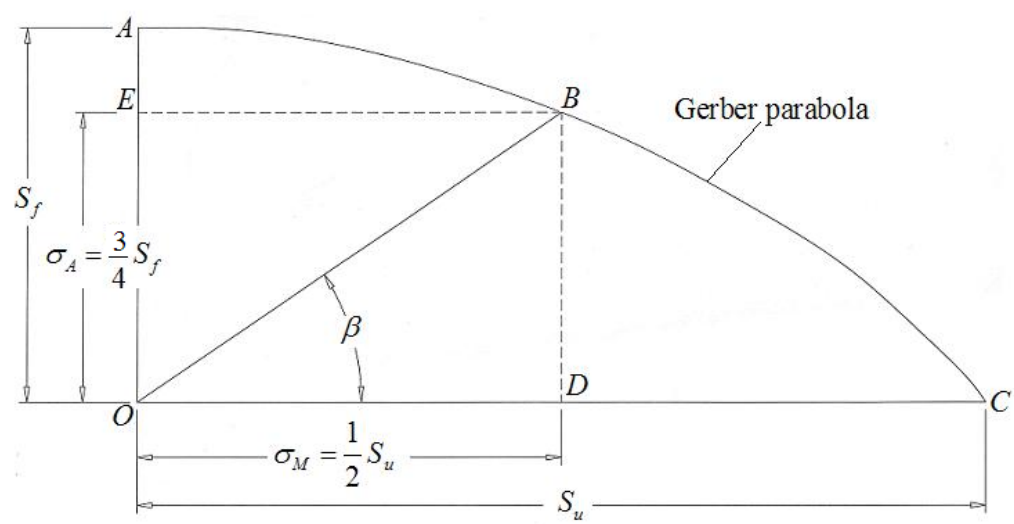

Figure 3. Bending fatigue design diagram

Equations $9 \mathrm{a}$ and $9 \mathrm{~b}$ depend on the service fatigue ratio $\psi_{\mathrm{s}}$ : the ratio of fatigue strength in service to ultimate tensile strength of materials. A design point is defined by the coordinates $\left(\sigma_{m}, k_{\sigma} \sigma_{a}\right)$ which has a load line that passes through the origin with a slope (Osakue, 2012) given by:

$$
\eta=\frac{k_{\sigma} \sigma_{a}}{\sigma_{m}}=\frac{k_{\sigma} M_{a}}{M_{m}}
$$

If $\eta$ is equal to or greater than the load line transition factor $\eta_{t}$, then the design point will be inside the region $\mathrm{OAB}$ in Figure 3 and dynamic fatigue failure regime applies. If $\eta$ is less than $\eta_{\mathrm{t}}$, the design point will be inside triangle $\mathrm{OBC}$ in Figure 3, and static fatigue failure regime applies.

\subsection{Dynamic Fatigue Failure Regime: $\eta \geq \eta_{t}$}

The design load capability in dynamic fatigue failure is determined by the service fatigue strength. If direct field measurements are made, $v_{f}$ is obtained from test results. However, laboratory fatigue tests on small polished specimens of the material of interest (Collins, Busby, \& Staab, 2010) can be used to estimate field or service fatigue strength by making use of adjustment or correction factors. In such a case, the service fatigue strength 
(Equation 11a) and coefficient of variation of the fatigue strength (Equation 11b) are estimated respectively as:

$$
\begin{gathered}
S_{f}=C_{s z} C_{s r} C_{t m} \psi_{o} S_{f}^{\prime} \\
v_{S}=v_{f}=\left[v_{s u}^{2}+v_{o}^{2}+v_{s z}^{2}+v_{s r}^{2}+v_{t m}^{2}\right]^{\frac{1}{2}}
\end{gathered}
$$

Based on the works of (Collins, Busby, \& Staab, 2010; Osakue, 2012), $\sigma_{e f}$ for tradition Gerber rule is:

$$
\begin{gathered}
\sigma_{e f}=\frac{k_{\sigma} \sigma_{a}}{1-\frac{1}{n_{m}^{2}}} \\
n_{m}=\frac{S_{u}}{\sigma_{m}}
\end{gathered}
$$

From the Appendix (Equation A10), the $\operatorname{cov}$ of $\sigma_{e f}$ is determined as:

$$
v_{\sigma}=\left[v_{k}^{2}+v_{F}^{2}+v_{l}^{2}+9 v_{h}^{2}+\left(\frac{2}{n_{m}^{2}-1}\right)^{2}\left(v_{F}^{2}+v_{l}^{2}+9 v_{h}^{2}+v_{u}^{2}\right)\right]^{\frac{1}{2}}
$$

During design sizing, the reliability factor is needed. Equation 13 is used to determine design model parameters variability and Equation $8 \mathrm{~b}$ is used to evaluate the reliability factor for a target failure probability. The section modulus for a component can then be estimated as:

$$
Z_{x} \geq \frac{K_{F} n_{z}}{S_{f}}\left[k_{\sigma} M_{a}+\frac{\psi_{s}}{2} M_{m}\right]
$$

Cross-sectional dimensions of the component section are determined for a rectangular beam as:

$$
\begin{gathered}
h=\left[6 \phi Z_{x}\right]^{\frac{1}{3}} \\
b=\frac{h}{\phi}
\end{gathered}
$$

For a solid round bar, the diameter of the component is:

$$
d=\left[\frac{32 Z_{x}}{\pi}\right]^{\frac{1}{3}}
$$

In design analysis, the section moduli are calculated or selected from Tables. For simple cross-sectional shapes like rectangle or circle, Equation $17 \mathrm{a}$ and Equation $17 \mathrm{~b}$ may be used respectively:

$$
\begin{aligned}
& Z_{x}=\frac{1}{6} b h^{2} \\
& Z_{x}=\frac{\pi}{32} d^{3}
\end{aligned}
$$

The induced nominal stresses at a point of maximum bending moments are then evaluated as:

$$
\begin{gathered}
\sigma_{a}=\frac{M_{a}}{Z_{x}} \\
\sigma_{m}=\frac{M_{m}}{Z_{x}}
\end{gathered}
$$


Substituting Equation 18 in Equation 12, the reliability factor is determined as:

$$
n_{z}=\frac{S_{f}}{\sigma_{e f}}
$$

Equation $7 \mathrm{~b}$ is used to determine the unit normal variate while Equation $8 \mathrm{a}$ is used to evaluate the reliability using the unit normal variate from Equation $7 \mathrm{~b}$ by referring to appropriate table for $\Phi(z)$.

\subsection{Static Fatigue Failure Regime: $\eta<\eta_{t}$}

The design load capability in static fatigue failure is determined by the service tensile strength. If direct field measurements are made, $v_{\mu}$ is obtained from test results. But, if the tensile data available are from laboratory tests on small polished specimens, then like the service fatigue strength, the service tensile strength (Equation 20a) and the coefficient of variation of the tensile strength (Equation 20b) are estimated respectively as:

$$
\begin{gathered}
S_{u}=C_{s z} C_{s r} C_{t m} S_{u}^{\prime} \\
v_{S}=v_{u}=\left[v_{s u}^{2}+v_{s z}^{2}+v_{s r}^{2}+v_{t m}^{2}\right]^{\frac{1}{2}}
\end{gathered}
$$

Based on the works of Osakue (2012), $\sigma_{e f}$ for traditional Gerber bending fatigue rule is:

$$
\begin{gathered}
\sigma_{e f}=\frac{\sigma_{m}}{\sqrt{1-\frac{1}{n_{a}}}} \\
n_{a}=\frac{S_{f}}{k_{\sigma} \sigma_{a}}
\end{gathered}
$$

From the Appendix (Equation A17), the cov of $\sigma_{e f}$ is:

$$
v_{\sigma}=\left[v_{F}^{2}+v_{l}^{2}+9 v_{h}^{2}+\frac{1}{4}\left(\frac{1}{n_{a}-1}\right)^{2}\left(v_{k}^{2}+v_{F}^{2}+v_{l}^{2}+9 v_{h}^{2}+v_{f}^{2}\right)\right]^{\frac{1}{2}}
$$

As in the dynamic fatigue regime, the reliability factor is needed during design sizing. Equation 22 is used to determine design model parameters variability, Equation $8 \mathrm{~b}$ is used to evaluate the reliability factor for a target failure probability. Then:

$$
Z_{x} \geq \frac{K_{F} n_{z}}{S_{u}}\left[\frac{k_{\sigma} M_{a}}{\eta_{t}}+M_{m}\right]
$$

Equations 15 and 16 are used for sectional dimensions and in design analysis; the stresses are evaluated using equations 17 and 18. Substituting Equation 18 in Equation 21, the reliability factor is determined as:

$$
n_{z}=\frac{S_{u}}{\sigma_{e f}}
$$

Equation $7 \mathrm{~b}$ is used to determine the unit normal variate while equation $8 \mathrm{a}$ is used to evaluate the reliability using the unit normal variate by referring to appropriate table for $\Phi(z)$.

\section{Some Applications of Models}

Two solutions are developed and three solutions are analyzed in this section. The design problem is a case of possible dynamic fatigue failure taken from Norton (2000). The first example is a design analysis of the solution provided in the reference from a probabilistic perspective based on the design model equations developed in this paper. The second and third examples are attempts to redesign the components of example 1 using probabilistic fatigue approach as presented in this paper. This example is used because it is described as a typical design problem (Norton, 2000).

\subsection{Example 1}

Figureure 4 shows one of two brackets attached to a machine frame. The brackets carry a combined fluctuating load varying from a minimum of $890 \mathrm{~N}$ to a maximum of 9,786 N (Norton, 2000); (data converted to SI Units by 
author). The load is shared equally by the brackets; the maximum allowed lateral deflection is $0.51 \mathrm{~mm}$ for each bracket, and each should be designed for $10^{9}$ load cycles. The load-time function is sinusoidal, maximum cantilever length is $152 \mathrm{~mm}$, and the operating temperature is $50{ }^{\circ} \mathrm{C}$. Trial dimensions are $b=51 \mathrm{~mm}, h=25.4$ $\mathrm{mm}, H=28.6 \mathrm{~mm}, r=12.7 \mathrm{~mm}$ and $l=127 \mathrm{~mm}$. The brackets will be machined to size from stocks. From Norton (2000), the value of $k_{\sigma}=1.16$ and $Z_{x}=5463.45 \mathrm{~mm}^{3}$. The brackets are to be made from SAE 1040 steel with $S_{u}=550 \mathrm{MPa}$ and $S_{f}=150 \mathrm{MPa}$ at $99.9 \%$ reliability.
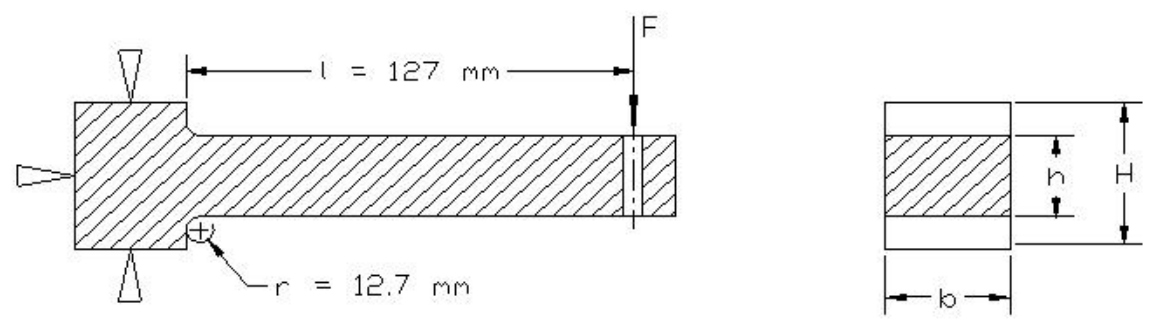

Figure 4. (Norton, 2000)

\subsubsection{Example 1 Solution}

The use of probability model in design requires the coefficients of variation of the design parameters. That is, variability of load, material properties, and geometric dimensions must be known for the benefit of probabilistic design to be realized. In house data on variability of design model parameters are the most reliable in probabilistic design. Most of the required variability information are probably available in current databases but are not processed or presented in the appropriate format. So it might take some effort in data gathering so that they are presented in mean and coefficient of variation format. For the example, Table 1 summarizes the coefficients of variation associated with the design parameters in the problems. Based on Table 1 and Equation $11 \mathrm{~b}$, the effective strength coefficient of variation was evaluated to be 0.207 . The expected $10^{9}$ load cycles for the brackets is in the range of infinite-life fatigue regime. This simplifies the estimation of the service fatigue strength as shown in Norton (2000). At 50\% reliability level the service fatigue strength is $S_{f}=200 \mathrm{MPa}$ (Osakue, 2012).

Based on the dimensions $b=51 \mathrm{~mm}, h=25.4 \mathrm{~mm}, H=28.6 \mathrm{~mm}, r=12.7 \mathrm{~mm}$, a design analysis was performed in an Excel Spreedsheet using Equations 11, 12, 13, 17, 18, 19, 7b and 8a. Table 2 summarizes this analysis.

Table 1. Coefficients of variation

\begin{tabular}{lc}
\hline Strength (COVs) & Value \\
\hline Basic fatigue strength (Shigley \& Mischke, 1996) & 0.080 \\
Tensile strength (Shigley \& Mischke, 1996) & 0.050 \\
Basic fatigue ratio (Shigley \& Mischke, 1996) & 0.140 \\
Size* & 0.001 \\
Surface finish (machined) (Shigley \& Mischke, 1996) & 0.120 \\
Temperature (Shigley \& Mischke, 1996) & 0.110 \\
\hline Stress (COVs) & Value \\
\hline Overload factor (Collins, Busby, \& Staab, 2010). & 0.050 \\
Length (Matthews, 2005) & 0.030 \\
Depth (Shigley \& Mischke, 1996) & 0.001 \\
Stress conc. factor (Shigley \& Mischke, 1996) & 0.110 \\
Miscellaneous (Matthews, 2005) & 0.050 \\
\hline
\end{tabular}

* Conservative estimate 
Table 2. Deterministic solution

\begin{tabular}{lc}
\hline \multicolumn{2}{c}{ Design Analysis } \\
\hline Section Properties & Value \\
\hline Major section modulus $\left(\mathrm{mm}^{3}\right)$ & 5463.5 \\
Minor section modulus $\left(\mathrm{mm}^{3}\right)$ & 11011 \\
\hline Stress Concentration Factors & Value \\
\hline Bending stress con. factor & 1.160 \\
Equivalent Loads & Value \\
Minor section modulus factor & 2.015 \\
Equivalent alternating moment $(\mathrm{Nmm})$ & 327640 \\
Equivalent mean moment (Nmm) & 338938 \\
\hline Effective Stress & Value \\
\hline Equivalent alternating stress (MPa) & 65.966 \\
Equivalent mean stress (MPa) & 68.240 \\
Mean stress to tensile strength ratio & 8.060 \\
Effective stress & 66.997 \\
\hline Reliability Assessment & Value \\
\hline Reliability factor & 2.985 \\
Effective stress cov & 0.134 \\
Unit normal variate & 4.421 \\
Reliability level (\%) & 99.9997 \\
\hline
\end{tabular}

\subsection{Example 2 Problem}

Redesign the brackets of Figure 4 so that $h$ and $H$ maintains the same ratio for a reliability of $99.9 \%$. The material and other conditions remain the same as stated in Example 1.

\subsubsection{Example 2 Solution}

As seen in Equation 8b, the reliability factor and reliability level are dependent in probabilistic design. So they cannot be independently specified as is often done in deterministic design. That is why two new design solutions (Example 2 and Example 3) are presented for example 1. The task in this problem is to determine the dimensions of the bar at the critical section which is at the fillet location in Figure 4. The shape of the cross-section is rectangular as shown on the right side of Figure 4. Economical beams generally have a height-width ratio of 2 to 4 Onuoye (2007), so a ratio of 3 was used for a trial size. The design sizing was performed in an Excel Spreedsheet using Equatio ns 11, 13, 14, 15, 8a and 8b. For $99.9 \%$ reliability, $k_{\sigma}=1.3$ was assumed for a trial solution. The section depth, $\mathrm{h}$ was calculated as $43.87 \mathrm{~mm}$ and width as $14.62 \mathrm{~mm}$. But the depth was chosen as $42 \mathrm{~mm}$ while the width was chosen as $15 \mathrm{~mm}$. With these chosen dimensions:

$$
H=1.125 \times 42=47.25 \mathrm{~mm}
$$

Use $H=48 \mathrm{~mm}$. Then

$$
\frac{H}{h}=\frac{48}{42}=1.143 \text { and } \frac{r}{h}=\frac{12.7}{42}=0.3024 .
$$

Based on the ratios 1.125 and 0.3175 and from Figure 4.36 (Norton2000), $k_{\sigma}^{\prime}$ was read to be 1.3 and $k_{\sigma}$ was evaluated to be $1.263 . k_{\sigma}^{\prime}$ and $k_{\sigma}$ are related by the notch sensitivity factor. Table 3 summarizes the design analysis for this solution.

\subsection{Example 3 Problem}

Redesign the brackets of Figure 4 so that $h$ and $H$ maintains the same ratio for a minimum reliability factor of 2.5. The material and conditions stated in Example 1 apply. 


\subsubsection{Example 3 Solution}

For a minimum reliability factor of $2.5, k_{\sigma}=1.3$ was again assumed for a trial solution. The section depth, $\mathrm{h}$ was calculated to be $45.87 \mathrm{~mm}$ and the width as $15.29 \mathrm{~mm}$. However the depth was chosen as $45 \mathrm{~mm}$ and the width was chosen as $15 \mathrm{~mm}$. With these dimensions:

$$
H=1.125 \times 45=50.63 \mathrm{~mm}
$$

Use $H=50 \mathrm{~mm}$. Then

$$
\frac{H}{h}=\frac{50}{45}=1.111 \text { and } \frac{r}{h}=\frac{12.7}{45}=0.282 .
$$

Based on the ratios 1.111 and 0.282 and from Figure 4.36 (Norton, 200), $k_{\sigma}^{\prime}$ was read to be 1.33 and $k_{\sigma}$ was evaluated to be 1.277. Table 4 summarizes the design analysis for this solution.

Table 3. 99.9\% Reliability solution

\begin{tabular}{lc}
\hline \multicolumn{2}{c}{ Design Analysis } \\
\hline Section Properties & Value \\
\hline Major section modulus $\left(\mathrm{mm}^{3}\right)$ & 4410 \\
Minor section modulus $\left(\mathrm{mm}^{3}\right)$ & 1575 \\
\hline Stress Concentration Factors & Value \\
\hline Bending stress con. factor & 1.263 \\
\hline Equivalent Loads & Value \\
\hline Minor section modulus factor & 0.357 \\
Equivalent alternating moment (Nmm) & 356732 \\
Equivalent mean moment (Nmm) & 338938 \\
\hline Effective Stress & Value \\
\hline Equivalent alternating stress (MPa) & 88.981 \\
Equivalent mean stress (MPa) & 84.542 \\
Mean stress to tensile strength ratio & 6.506 \\
Effective stress (MPa) & 91.134 \\
\hline Reliability Assessment & Value \\
\hline Reliability factor & 2.195 \\
Effective stress cov & 0.134 \\
Unit normal variate & 3.163 \\
Reliability level (\%) & 99.92 \\
\hline
\end{tabular}


Table 4. 2.5 Reliability factor

\begin{tabular}{lc}
\hline \multicolumn{2}{c}{ Design Analysis } \\
\hline Section Properties & Value \\
\hline Major section modulus $\left(\mathrm{mm}^{3}\right)$ & 5063 \\
Minor section modulus $\left(\mathrm{mm}^{3}\right)$ & 1688 \\
\hline Stress Concentration Factors & Value \\
\hline Bending stress con. factor & 1.277 \\
\hline Equivalent Loads & Value \\
\hline Minor section modulus factor & 0.333 \\
Equivalent alternating moment $(\mathrm{Nmm})$ & 360686 \\
Equivalent mean moment (Nmm) & 338938 \\
\hline Effective Stress & Value \\
\hline Equivalent alternating stress (MPa) & 78.364 \\
Equivalent mean stress (MPa) & 73.639 \\
Mean stress to tensile strength ratio & 7.469 \\
Effective stress (MPa) & 79.794 \\
\hline Reliability Assessment & Value \\
\hline Reliability factor & 2.506 \\
Effective stress cov & 0.134 \\
Unit normal variate & 3.706 \\
Reliability level (\%) & 99.989 \\
\hline
\end{tabular}

\section{Solutions' Comparison}

Table 5 is a summary of the three solutions to the example problem. It shows the deterministic solution gave very conservative results in all design parameters considered. The next conservative results are from the 2.5 minimum reliability factor constrain. The optimum results are based on the desired reliability goal of $99.9 \%$. The reliability factor of 2.2 for this solution is based on the desired failure probability of $0.1 \%$ and cannot be independently specified. The deterministic solution gives a $20 \%$ increase in reliability factor over the required value and $43 \%$ increase in the unit normal variate required, yielding a higher reliability of 99.9997 . The optimum solution yields $12 \%$ decrease in reliability factor and $2.3 \%$ increase in the unit normal variate required. While the design reliability requirement is "three nines", the deterministic solution yields almost "six nines"! Clearly, if the dimensions for the deterministic solution were adopted as final values, then it would appear to have been a case of over-design. This would support the view of Kalpakjian and Schmid (2001), who noted that over-design is not an uncommon issue with past designs.

Table 5. Solutions' summary

\begin{tabular}{lccc}
\hline \multirow{2}{*}{ Design Parameter } & \multicolumn{3}{c}{ Solutions } \\
\cline { 2 - 4 } & Deterministic & $\mathbf{9 9 . 9 \%}$ Reliability & $\mathbf{2 . 5}$ Reliability Factor \\
\hline Effective stress (MPa) & 67 & 91 & 80 \\
Reliability factor & 2.99 & 2.20 & 2.51 \\
Unit normal variate & 4.42 & 3.16 & 3.71 \\
Reliability (\%) & 99.9997 & 99.92 & 99.989 \\
\hline
\end{tabular}


The deflections at the point of load application and at the end of the bracket were computed for a cantilever beam (Figure 4). The computed deflection values are compared in Table 6 for the three solutions with the allowable. These values are much lower than the maximum allowable value of $0.51 \mathrm{~mm}$, indicating that the three design solutions satisfy the deflection requirement.

Table 6. Deflection comparison

\begin{tabular}{lccc}
\hline \multirow{2}{*}{ Design Parameter } & \multicolumn{3}{c}{ Solutions } \\
\cline { 2 - 4 } & Deterministic & $\mathbf{9 9 . 9 \%}$ Reliability & 2.5 Reliability Factor \\
\hline Deflection at load point $(\mathrm{mm})(\mathrm{mm})$ & 0.252 & 0.174 & 0.142 \\
Deflection at bar end $(\mathrm{mm})$ & 0.300 & 0.225 & 0.184 \\
Bar end deflection $(\%)$ & 59 & 44 & 36 \\
\hline
\end{tabular}

Table 7 summarizes the cross-sectional dimensions and area of the bar. The cross-sectional area of the optimum solution is a $51 \%$ reduction in area compared to the deterministic solution. Practically, this translates to a $51 \%$ reduction in weight or material cost per component at $44 \%$ of maximum allowable deflection. Certainly a $51 \%$ savings in material cost could translate into thousands if not millions of dollars in savings in a large volume production considering that two components per equipment are required!

Table 7. Size comparison

\begin{tabular}{lccc}
\hline \multirow{2}{*}{ Design Parameter } & \multicolumn{3}{c}{ Solutions } \\
\cline { 2 - 4 } & Deterministic & $\mathbf{9 9 . 9 \%}$ Reliability & 2.5 Reliability Factor \\
\hline Depth $(\mathrm{mm})$ & 25.4 & 42 & 45 \\
Width $(\mathrm{mm})$ & 51 & 15 & 15 \\
Area $\left(\mathrm{mm}^{2}\right)$ & 1295 & 630 & 675 \\
Area comparison $(\%)$ & 100 & 49 & 52 \\
\hline
\end{tabular}

\section{Conclusions}

A probabilistic fatigue design approach based on the Gerber failure rule has been presented. The model design parameters use mean values to estimate expected design results while the reliability of the design is evaluated using the coefficients of variation of the design parameters. The coefficients of variation of strength and stress were developed using sensitivity analysis based on first order Taylor series expansion of design relationships. A typical design problem was analyzed and redesigned using the approach. As can be seen from Table 7, significant reduction in component mass can be realized when probabilistic design is adopted. A more accurate assessment of risk is possible since the reliability factor is dependent on an adopted failure probability. To make probabilistic design more wide spread, it is recommended that design data presentation need a new format (Shigley \& Mischke, 1996): mean values and coefficients of variation (covs). To facilitate distinction between ductile and brittle materials, it is also recommended that the mean and coefficient of variation values of percentage elongation of engineering materials be reported. Since more than $5 \%$ elongation is conventionally taken for ductile materials, it will be thus easy to decide when choosing materials for fatigue design applications. For probabilistic fatigue design, data on the mean and coefficient of variation of tensile strength, fatigue strength, and percentage elongation are therefore recommended.

\section{Acknowledgements}

This study was supported in parts with funds from COST Faculty Development Fund of Texas Southern University, Houston, Texas.

\section{References}

Ashby, F. M., \& Jones, D. H. R. (1986). Engineering Materials 2: An Introduction to Microstructure, Processing and Design. Oxford: Pergamon.

Childs, P. R. N. (2004). Mechanical design (2nd ed.). New York: Prentice-Hall. 
Collins, A. J., Busby, H., \& Staab, G. (2010). Mechanical Design of Machine Element. New Jersey: John Wiley $\&$ Sons.

Cullimore, B., \& Tsuyuki, G. (2002). Reliability Engineering and Robust Design: New Methods for Thermal/Fluid Engineering. Proc. of $11^{\text {th }}$ Thermal and Fluid Analysis Workshop, pp. 225-240

Dieter, E. G. (1976). Mechanical Metallurgy (2nd ed., Chap. 12). New York: McGraw-Hill.

Hidgon, A., Ohseen, E. H., Stiles, W. B., \& Weesa, J. A. (1967). Mechanics of Materials (2nd Ed., Chap. 10). New York: Wiley \& Sons.

JJS, Probabilistic Design. (n.d.). Retreived October 12, 2013 from http://telicthoughts.com/probabilistic-design/

Johnson, C. R. (1980). Optimum Design of Mechanical Elements. New York: Wiley \& Sons.

Juvinall, R. C. (1983). Fundamentals of Machine Components Design (pp. 200-230). New York: Wiley and Sons.

Kalpakjian, S., \& Schmid, S. R. (2001). Manufacturing Engineering and Technology (4th ed.). Upper Saddle River, New Jersey: Pearson Prentice Hall.

Koch, P. (2002). Probabilistic Design: Optimization for Six-Sigma Quality. $43^{\text {rd }}$ AIAA/ASME/ASCE/AHS/ASC Conference, Denver, Colorado. http://dx.doi.org/10.2514/6.2002-1471.

Kravchenko, P. Y. E. (1964). Fatigue Resistance. New York: Pergamon.

Lognormal Distribution. (n.d). In Engineering Statistics Handbook. Retrieved on October 12, 2012 from http://itl.nist.gov/div898/handbook/eda/section3/eda3669.htm.

Matthews, C. (2005). ASME Engineer's Data Book (2nd ed., p.63 \& 87). New York: ASME Press.

Mischke, C. R. (1996). Statistical Considerations. In J. E. Shigley \& C. R. Mischke (Chief Editors), Standard Handbook of Machine Design. New York: McGraw-Hill.

Mott, R, L. (2008). Applied Strength of Materials (5th ed.). Upper Saddle River, New Jersey: Pearson Prentice Hall.

Norton, R. L. (2000). Machine Design: An Integrated Approach. Upper Saddle River, New Jersey: Prentice-Hall.

Onuoye, B., \& Kane, K. (2007). Statics and Strength of Materials for Architecture and Building Construction. Upper Saddle River, New Jersey: Prentice-Hall.

Osakue, E. E. (2012). A Linearized Gerber Fatigue Model. International Journal of Modern Engineering, 12(1), 64-72.

Osakue, E. E., Anetor, L., \& Odetunde, C. (2012). A Generalized Linearized Gerber Fatigue Model. Machine Design, 4, 1-10.

Pandit, S. M., \& Shiekh, A. K., (1980). Reliability and Optimal Replacement via Coefficient of Variation. Journal of Machine Design, 102, 761-768. http://dx.doi.org/10.1115/1.3254819.

Reshetov, D., Ivanov, A., \& Fadeev, V. (1980). Reliability of Machines. Moscow: MIR.

Sachs, N., (1999). Root Cause Failure Analysis-Interpretation of Fatigue Failures. Reliability Magazine.

Shigley, E. J., \& Mitchell, L. D. (1983). Mechanical Engineering Design. New York: McGraw-Hill.

Shigley, J. E., \& Mischke, C. R. (1996). Standard Handbook of Machine Design. New York: McGraw-Hill.

Spotts, M. F. (1985). Design of Machine Elements (pp. 101-131). Englewood Cliffs: Prentice-Hall.

Taguchi, G. (1992). Taguchi Methods: Research and Development (pp. 32-33, 49-50). Dearborn: ASI.

Understanding Probabilistic Design. (n.d.). Retrieved October 12, 2012, from http://www.kxcad.net/ansys/ANSYS/ansyshelp/Hlp_G_ADVPDS1.html.

Wang, H., Kim, N. H., \& Kim, Y. (2006). Safety Envelope for Load Tolerance and its Application to Fatigue Reliability. Journal of Mechanical Design, 128, 919-927. http://dx.doi.org/10.1115/1.2204971 


\section{Appendix: Design Model Parameters' Variability}

Mischke (1996) stated that deterministic and familiar engineering computations are useful in stochastic problems if mean values are used. Therefore, if the mean and standard deviation or coefficients of variation of design parameters are available, a probabilistic analysis is possible. In this study, the design variables are characterized by the means and coefficients of variation of sample data. The use of the coefficient of variation is particularly desirable since it can be conveniently summarized for a large class of materials and parts (Pandit \& Shiekh, 1980). According to Mischke (1996), sum of variates from any distribution tend asymptotically to lognormal. Products, quotients, and exponents of lognormals are lognormals. Products of variates from any distribution tend asymptotically to lognormal. Since model design formulas in mechanical and structural problems consist of products, quotients or sums of products and quotients of design parameters, the lognormal probability distribution is a strong candidate for application in probabilistic design.

Suppose a function $\chi$, has the random variables $x_{1}, x_{2}, x_{3} \ldots \ldots . x_{n}$ as independent variables. Then:

$$
\chi=f\left(x_{1}, x_{2}, x_{3} \ldots \ldots x_{n}\right)
$$

For a first order estimate, the mean and standard deviation of $\chi$ are respectively:

$$
\begin{gathered}
\mu_{\chi}=f\left(\mu_{x 1}, \mu_{x 2}, \mu_{x 3} \ldots \ldots . . \mu_{x n}\right) \\
s_{\chi}=\sqrt{\sum_{i=1}^{n}\left(\frac{\partial \chi}{\partial x_{i}}\right)^{2} s_{x_{i}}^{2}}
\end{gathered}
$$

The coefficient of variation is the ratio of standard deviation to the mean value.

$$
\begin{aligned}
& v_{\chi}=\frac{s_{\chi}}{\mu_{\chi}} \\
& s_{\chi}=v_{\chi} \mu_{\chi}
\end{aligned}
$$

In evaluating the coefficient of variation, the power rule can be applied to the design parameters followed by simplification of the expression for coefficient of variation. The power rule requires the product of the square of the coefficient of variation of a parameter and its exponent in a formula. That is (Mischke, 1996):

$$
\begin{gathered}
y=K x_{1}^{a} x_{2}^{b} x_{3}^{c} \\
v_{y}=\left[a^{2} v_{x 1}^{2}+b^{2} v_{x 2}^{2}+c^{2} v_{x 3}^{2}\right]^{\frac{1}{2}}
\end{gathered}
$$

Now engineering design models are approximations of reality and formulations for the same problem vary. However, simplified models in engineering design have been in practice for over two hundred years. They are generally sufficiently accurate to about $\pm 10 \%$ of reality (Matthews, 2005). To account for this variation, a miscellaneous coefficient of variation $\left(v_{m i s}\right)$ seems justified in probabilistic design and a value of $5 \%$ is suggested.

\section{Gerber Failure Model and Variability}

In Figure 3, the Gerber fatigue design space is divided into two regimes: dynamic and static failure regimes. In the following sections, expressions for the coefficients of variation of the expected stress from external loads will be developed.

\section{Dynamic Fatigue Failure}

In the dynamic fatigue failure regime, the effective normal stress is projected on the vertical axis as shown in 
Figure 3. An effective normal stress can be defined for the dynamic fatigue failure regime (Collins, Busby, \& Staab, 2010; Osakue, 2012):

$$
\begin{gathered}
\sigma_{e f}=\frac{k_{\sigma} \sigma_{a}}{\mathrm{Y}} \\
v_{\sigma}=\sqrt{v_{m i s}^{2}+v_{k}^{2}+v_{a}^{2}+v_{Y}^{2}}
\end{gathered}
$$

Equation A6b is obtained by applying the power rule (Equation A4) to Equation A6a and:

$$
\begin{gathered}
\mathrm{Y}=1-\left(\frac{\sigma_{m}}{S_{u}}\right)^{2} \\
s_{Y}^{2}=\left(\frac{\partial Y}{\partial \sigma_{m}}\right)^{2}\left(v_{m} \sigma_{m}\right)^{2}+\left(\frac{\partial Y}{\partial S_{u}}\right)^{2}\left(v_{u} S_{u}\right)^{2}
\end{gathered}
$$

From Equation A6a:

$$
\left(\frac{\partial Y}{\partial \sigma_{m}}\right)=\frac{-2 \sigma_{m}}{S_{u}^{2}} \quad\left(\frac{\partial Y}{\partial S_{u}}\right)=\frac{2 \sigma_{m}^{2}}{S_{u}^{3}}
$$

Substitute Equation A7 in Equation A6b and simplify:

$$
\begin{gathered}
s_{Y}=2\left(\frac{\sigma_{m}}{S_{u}}\right)^{2}\left[v_{m}{ }^{2}+v_{u}{ }^{2}\right]^{\frac{1}{2}} \\
\text { and } v_{Y}=\frac{s_{Y}}{Y} \quad \frac{2}{n_{m}^{2}-1}\left[v_{m}{ }^{2}+v_{u}{ }^{2}\right]^{\frac{1}{2}} \\
n_{m}=\frac{S_{u}}{\sigma_{m}}
\end{gathered}
$$

Substitute Equations A9b, A10, and A20 into Equation A5b:

$$
v_{\sigma}=\left[v_{m i s}^{2}+v_{k}^{2}+v_{F}^{2}+v_{l}^{2}+9 v_{h}^{2}+\left(\frac{2}{n_{m}^{2}-1}\right)^{2}\left(v_{F}^{2}+v_{l}^{2}+9 v_{h}^{2}+v_{u}^{2}\right)\right]^{\frac{1}{2}}
$$

\section{Static Fatigue Failure}

In the static fatigue failure regime, the effective normal stress is projected on the horizontal axis as shown in Figure 3; the effective mean normal stress is (Osakue, 2012):

$$
\begin{gathered}
\sigma_{e f}=\frac{\sigma_{m}}{\sqrt{1-\frac{k_{\sigma} \sigma_{a}}{S_{f}}}}=\frac{\sigma_{m}}{\sqrt{Y}} \\
v_{\sigma}=\sqrt{v_{m i s}^{2}+v_{m}^{2}+\frac{1}{4} v_{Y}^{2}}
\end{gathered}
$$

Where 


$$
Y=1-\frac{k_{\sigma} \sigma_{a}}{S_{f}}
$$

Now

$$
s_{Y}^{2}=\left(\frac{\partial Y}{\partial k_{\sigma}}\right)^{2}\left(v_{k} k_{\sigma}\right)^{2}+\left(\frac{\partial Y}{\partial \sigma_{a}}\right)^{2}\left(v_{a} \sigma_{a}\right)^{2}+\left(\frac{\partial Y}{\partial S_{f}}\right)^{2}\left(v_{f} S_{f}\right)^{2}
$$

From Equation A12

$$
\left(\frac{\partial Y}{\partial k_{\sigma}}\right)=-\frac{\sigma_{a}}{S_{f}} ; \quad\left(\frac{\partial Y}{\partial \sigma_{\sigma}}\right)=-\frac{k_{\sigma}}{S_{f}} ; \quad\left(\frac{\partial Y}{\partial S_{f}}\right)=\frac{k_{\sigma} \sigma_{a}}{S_{f}^{2}}
$$

Substitute Equation A14 in Equation A13 and simplify:

$$
\begin{gathered}
s_{Y}=\left(\frac{k_{\sigma} \sigma_{a}}{S_{f}}\right)\left[v_{k}^{2}+v_{a}^{2}+v_{f}^{2}\right]^{\frac{1}{2}} \\
v_{Y}=\frac{s_{Y}}{Y}=\frac{1}{n_{a}-1}\left[v_{k}^{2}+v_{a}^{2}+v_{f}^{2}\right]^{\frac{1}{2}} \\
n_{a}=\frac{S_{f}}{k_{\sigma} \sigma_{a}}
\end{gathered}
$$

Then

$$
v_{\sigma}=\left[v_{F}^{2}+v_{l}^{2}+9 v_{h}^{2}+\frac{1}{4}\left(\frac{1}{n_{a}-1}\right)^{2}\left(v_{k}^{2}+v_{F}^{2}+v_{l}^{2}+9 v_{h}^{2}+v_{f}^{2}\right)\right]^{\frac{1}{2}}
$$

\section{Bending Stress Variability}

Bending stress, also referred to as flexural stress, is caused by the bending effect of a lateral force. It varies from zero at the neutral axis to a maximum on the surface of a member. FigureA1 shows the configuration of a beam revealing the orthographic views. The beam cross-section is shown on the lower right of the Figure. The width of the beam is assumed proportional to the depth with $\varphi$ as the shape ratio.
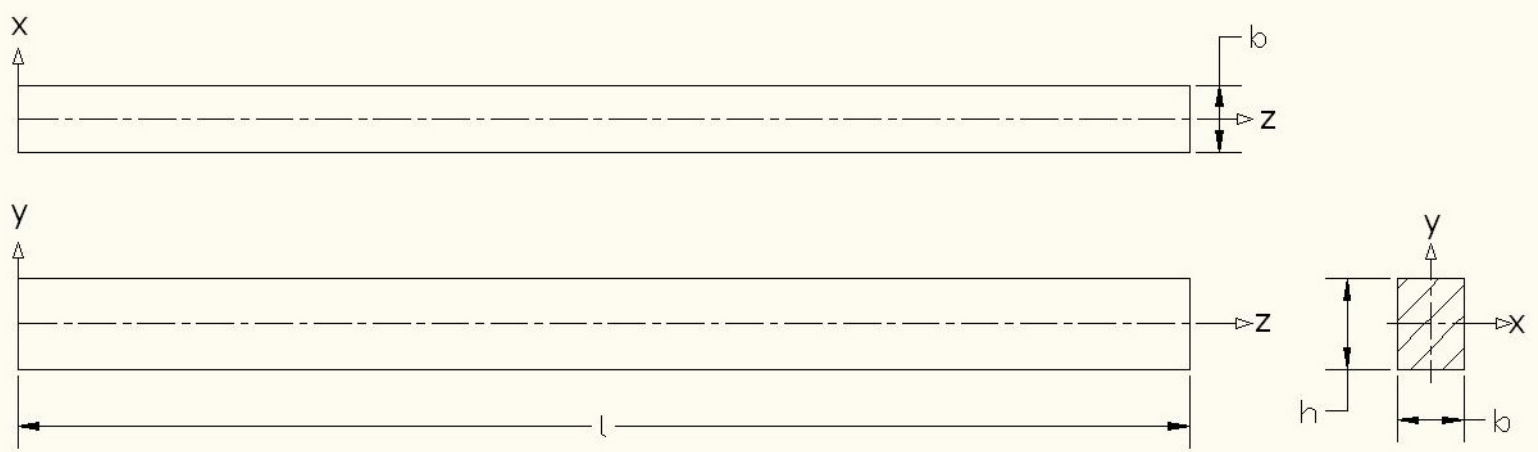

Figure A1. Beam geometry 
The bending stress at a section is:

$$
\sigma=\frac{M}{Z}
$$

where

$$
\begin{gathered}
M=\beta_{m} l F \\
\mathrm{Z}=\frac{b h^{2}}{6}=\frac{h^{3}}{6 \phi} \\
b=\frac{h}{\phi}
\end{gathered}
$$

In Equation A19a, the maximum bending moment $M$ on a beam from a concentrated load is expressed in a general form. The parameter $\beta_{m}$ depends on the position of the load on the beam span and the end fixity of the beam. For instance; in the case of a simply supported beam, $\beta_{m}=0.25$ if the load is at mid span and $\beta_{m}=1$ for a cantilever beam carrying a concentrated load at its free end. Substitute Equation A19 in equation, A18, and simply to symbolic form:

$$
\begin{gathered}
\sigma=\frac{6 \phi \beta_{m} l F}{h^{3}}=f\left(l, F, h^{3}\right) \\
v_{\sigma}=\frac{s_{\sigma}}{\sigma}=\left[v_{l}^{2}+v_{F}^{2}+9 v_{h}^{2}\right]^{\frac{1}{2}}
\end{gathered}
$$

Equation A20b is obtained by applying the power rule to equation A20a. In fatigue design, Equations A20a and A20b apply separately to $F_{m}$ and $F_{a}$ so:

$$
v_{m}=v_{a}=\sqrt{v_{F}^{2}+v_{l}^{2}+9 v_{h}^{2}}
$$

\section{Nomenclature}

$$
\begin{array}{ll}
\psi_{s}= & \text { service fatigue ratio } \\
\psi_{o}= & \text { basic fatigue ratio } \\
\beta= & \text { load line transition angle } \\
\beta_{m}= & \text { bending moment factor } \\
\eta= & \text { load line slope factor } \\
\eta_{t}= & \text { load line slope transition factor in fatigue } \\
\sigma_{A}= & \text { Gerber nominal alternating service stress } \\
\sigma_{a}= & \text { alternating normal service stress } \\
\sigma_{m}= & \text { mean normal service stress } \\
\sigma_{e f}= & \text { effective service bending stress } \\
k_{\sigma}= & \text { service bending stress concentration factor } \\
k_{\sigma}^{\prime}= & \text { theoretical bending stress concentration factor } \\
Z_{x}= & \text { section modulus of member about x-axis } \\
Z= & \text { section modulus of member } \\
n_{m}= & \text { mean stress ratio relative to tensile strength } \\
\sigma_{M}= & \text { Gerber nominal mean service stress } \\
\sigma= & \text { nominal bending stress } \\
n_{a}= & \text { ratio of effective alternative stress to fatigue strength }
\end{array}
$$




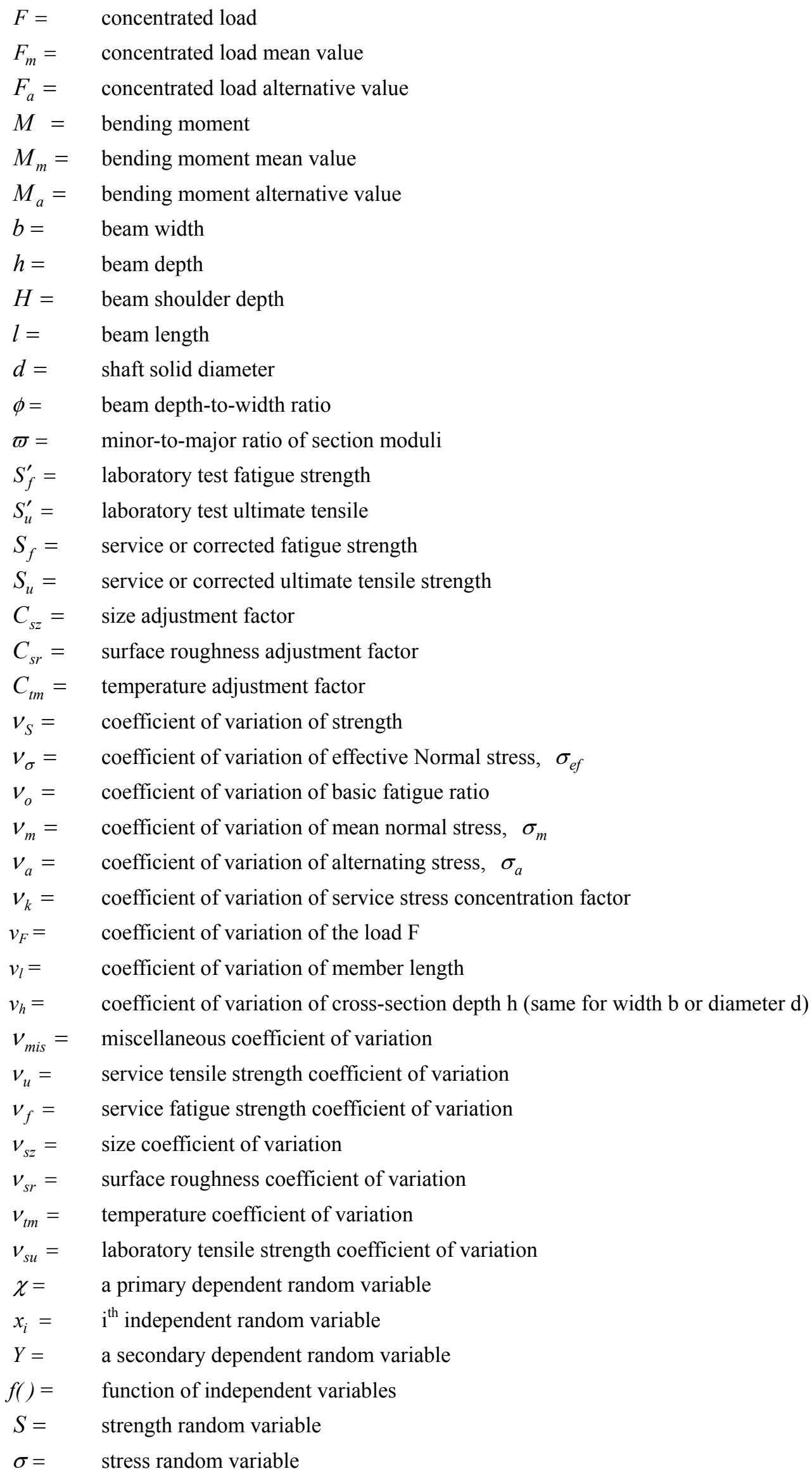




$\begin{array}{ll}x= & \text { strength lognormal random variable } \\ y= & \text { stress lognormal random variable } \\ q= & \text { failure stress lognormal random variable } \\ \mu= & \text { mean value variable } \\ s= & \text { standard deviation variable } \\ \mu_{S}= & \text { strength variable mean value } \\ \mu_{\sigma}= & \text { stress variable mean value } \\ \mu_{x}= & \text { strength lognormal variable mean value } \\ \mu_{y}= & \text { stress lognormal variable mean value } \\ \mu_{q}= & \text { failure stress lognormal variable mean value } \\ s_{x}= & \text { strength lognormal standard deviation } \\ s_{y}= & \text { stress lognormal standard deviation } \\ s_{q}= & \text { failure lognormal standard deviation } \\ z= & \text { unit normal variate } \\ n_{z}= & \text { design reliability factor at } z \\ R_{z}= & \text { reliability at } z \\ \Phi= & \text { cumulative probability density function } \\ r= & \text { fillet radius } \\ K= & \text { generic factor } \\ a, b, c= & \text { functional indices }\end{array}$

